\title{
Simulation study of the aerosol information content in OMI spectral reflectance measurements
}

\author{
B. Veihelmann, P. F. Levelt, P. Stammes, and J. P. Veefkind \\ Royal Netherlands Meteorological Institute (KNMI), P.O. Box 201, 3730 AE De Bilt, The Netherlands \\ Received: 20 November 2006 - Published in Atmos. Chem. Phys. Discuss.: 5 February 2007 \\ Revised: 8 May 2007 - Accepted: 29 May 2007 - Published: 18 June 2007
}

\begin{abstract}
The Ozone Monitoring Instrument (OMI) is an imaging UV-VIS solar backscatter spectrometer and is designed and used primarily to retrieve trace gases like $\mathrm{O}_{3}$ and $\mathrm{NO}_{2}$ from the measured Earth reflectance spectrum in the UV-visible $(270-500 \mathrm{~nm})$. However, also aerosols are an important science target of OMI. The multi-wavelength algorithm is used to retrieve aerosol parameters from OMI spectral reflectance measurements in up to 20 wavelength bands. A Principal Component Analysis (PCA) is performed to quantify the information content of OMI reflectance measurements on aerosols and to assess the capability of the multi-wavelength algorithm to discern various aerosol types. This analysis is applied to synthetic reflectance measurements for desert dust, biomass burning aerosols, and weakly absorbing anthropogenic aerosol with a variety of aerosol optical thicknesses, aerosol layer altitudes, refractive indices and size distributions. The range of aerosol parameters considered covers the natural variability of tropospheric aerosols. This theoretical analysis is performed for a large number of scenarios with various geometries and surface albedo spectra for ocean, soil and vegetation. When the surface albedo spectrum is accurately known and clouds are absent, OMI reflectance measurements have 2 to 4 degrees of freedom that can be attributed to aerosol parameters. This information content depends on the observation geometry and the surface albedo spectrum. An additional wavelength band is evaluated, that comprises the $\mathrm{O}_{2}-\mathrm{O}_{2}$ absorption band at a wavelength of $477 \mathrm{~nm}$. It is found that this wavelength band adds significantly more information than any other individual band.
\end{abstract}

Correspondence to: B. Veihelmann

(ben.veihelmann@knmi.nl)

\section{Introduction}

Several satellite instruments measuring backscattered solar radiation are currently used to monitor atmospheric aerosols. The characterization of aerosols using satellite observations is challenging since aerosols vary in many respects such as amount, composition, phase, size, particle shape and vertical distribution. In order to determine as many relevant aerosol parameters as possible, radiometric and polarimetric observations in a broad wavelength range with many viewing angles and a high spatial and spectral resolution would be optimal (Chowdhary et al., 2001). However, such measurements are technically challenging. Until now only POLDER (POLarization and Directionality of the Earth's Reflectances) uses polarization data for aerosol retrieval (Deuzé et al., 2000, 2001). Most satellite instruments measuring aerosols with global coverage are using radiometry only and provide only a subset of the required information (cf. Tanré et al., 1997, for MODIS (Moderate Resolution Imaging Spectroradiometer); Mishchenko et al., 1999, for AVHRR (Advanced Very High Resolution Radiometer); Diner et al., 1999, for MISR (Multiangle Imaging SpectroRadiometer)). In this case, a subset of aerosol parameters is retrieved (e.g. aerosol optical thickness and single scattering albedo) and a-priori information is used for aerosol parameters, which cannot be retrieved from the measurement. Various studies have been made to quantify the information content of satellite measurements of the solar backscatter on aerosol. Tanré et al. (1996) report that one to two parameters of the size distribution can be retrieved from observations with MODIS in the wavelength range from $470 \mathrm{~nm}$ to $2130 \mathrm{~nm}$. Hasekamp and Landgraf (2005) report that observations using GOME-II in the wavelength range from $300 \mathrm{~nm}$ to $800 \mathrm{~nm}$ contain 3.5 to 5 independent pieces of information when only intensity measurements are evaluated. In this study the information content of measurements of the Ozone Monitoring Instrument (OMI) on aerosol is investigated.

Published by Copernicus Publications on behalf of the European Geosciences Union. 


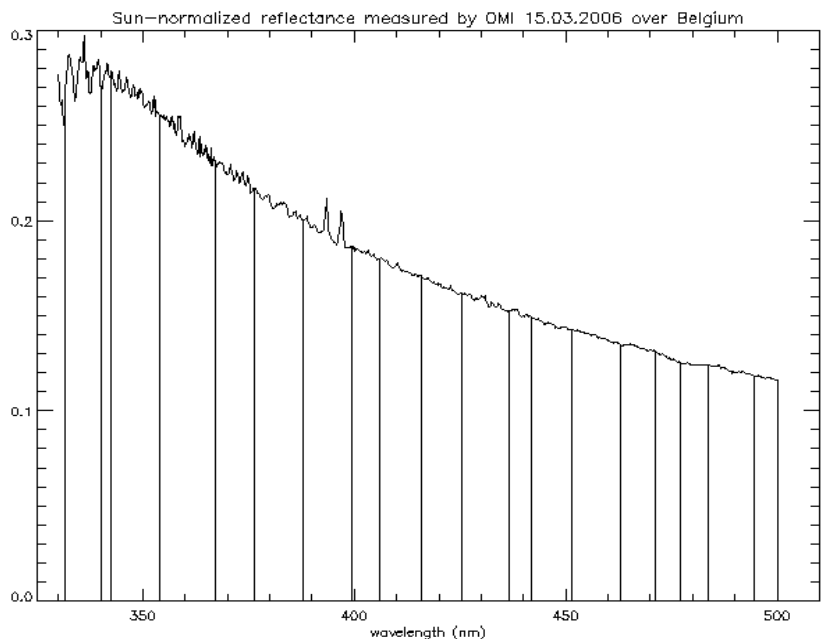

Fig. 1. Example for an OMI reflectance measurement and wavelength bands used in the multi-wavelength aerosol algorithm.

The OMI instrument is an imaging UV-VIS solar backscatter spectrometer (Levelt et al., 2006a). It is a DutchFinnish instrument onboard the NASA satellite EOS-Aura that has been launched in July 2004. The Aura platform moves on a sun synchronous polar orbit with an equator crossing-time at 13:38 local time (ascending node). With a novel detector concept using a 2-D CCD array radiance spectra of the solar backscatter are measured simultaneously on a $2600 \mathrm{~km}$ wide swath and global coverage is achieved on a daily basis. The (binned) nadir pixel size is about $13 \times 24 \mathrm{~km}^{2}$. Due to this relatively small pixel size, more than $20 \%$ of the pixels have a cloud fraction of 0.05 or lower (Kerridge et al., 2001). This is an advantage with respect to other satellite spectrometers with a larger footprint such as the Global Ozone Monitoring Experiment-2 (GOME-2) or the SCanning Imaging Absorption spectroMeter for Atmospheric CHartographY (SCIAMACHY) especially when tropospheric constituents are measured. OMI measures in the wavelength range from $270 \mathrm{~nm}$ to $500 \mathrm{~nm}$ with a spectral resolution of $0.45 \mathrm{~nm}$ in the ultraviolet (UV-2 channel) and $0.63 \mathrm{~nm}$ in the visible. Solar irradiance spectra are measured on a daily basis with the same detectors used for the radiance measurements. Atmospheric parameters are derived from the sun-normalized radiance spectrum (also referred to as reflectance spectrum hereafter) defined as

$R(\lambda)=\frac{\pi E(\lambda)}{\cos \left(\theta_{s}\right) F(\lambda)}$,

where $E(\lambda)$ and $F(\lambda)$ are the radiance and the solar irradiance spectrum respectively and $\theta_{s}$ is the solar zenith angle. An example for an OMI reflectance measurement is shown in Fig. 1. Evaluating the reflectance has the advantage that various instrument effects cancel out. The OMI instrument is used to measure atmospheric $\mathrm{O}_{3}, \mathrm{SO}_{2}, \mathrm{NO}_{2}$, aerosols, clouds and several minor atmospheric trace gases.
Table 1. Central wavelengths $\lambda$ of the bands used in the multiwavelength algorithm.

\begin{tabular}{ll}
\hline Band Nr. & $\lambda(\mathrm{nm})$ \\
\hline 1 & 331.7 \\
2 & 340.0 \\
3 & 342.5 \\
4 & 354.0 \\
5 & 367.0 \\
6 & 376.5 \\
7 & 388.0 \\
8 & 399.5 \\
9 & 406.0 \\
10 & 416.0 \\
11 & 425.5 \\
12 & 436.5 \\
13 & 442.0 \\
14 & 451.5 \\
15 & 463.0 \\
16 & 471.0 \\
17 & 477.0 \\
18 & 483.5 \\
19 & 494.5 \\
20 & 500.0 \\
\hline
\end{tabular}

Although the instrument concept is not optimized for monitoring aerosol, OMI reflectance measurements are sensitive to various aerosol parameters (Torres et al., 2002a, b). UV absorbing aerosols, like desert dust and biomass burning aerosols can be detected using OMI reflectance measurements due to their spectral contrast to Rayleigh scattering (Torres et al., 1998). Mineral dust aerosol can be distinguished from other aerosol types due to the absorption of mineral particles in the UV. As compared to longer wavelengths, the Earth's reflectance in the UV is less sensitive to the surface albedo. This is partly because of the rather low values of the surface albedo of both ocean and land in this wavelength range, and partly because the relative contribution of the surface reflection to the signal at the top of the atmosphere is smaller than at longer wavelengths. Hence, the information of OMI reflectance measurements on aerosols is particularly valuable for a global data set including ocean and land. Also, OMI can add complementary information in combined retrievals with other instruments such as MODIS that do not measure in the UV.

Two algorithms are applied to retrieve aerosol parameters from OMI reflectance measurements, referred to as the nearUV algorithm and the multi-wavelength algorithm respectively. The near-UV algorithm uses measurements at $354 \mathrm{~nm}$ and $388 \mathrm{~nm}$. It is based on the inversion procedure that has been used for aerosol retrievals from measurements of the Total Ozone Mapping Spectrometer (TOMS) (Torres et al., 1998, 2002a) using measurements at 340 and $380 \mathrm{~nm}$. It has 
been shown that one or two aerosol parameters, namely the Aerosol Optical Thickness (AOT) and the Single-Scattering Albedo (SSA), can be retrieved independently using the nearUV algorithm. The multi-wavelength algorithm uses up to 20 wavelength bands between $331 \mathrm{~nm}$ and $500 \mathrm{~nm}$ specified in Table 1 (Torres, 2002b) (see also Fig. 1). Wavelengths longer than $500 \mathrm{~nm}$ are outside the spectral range of the OMI instrument. The sensitivity of the signal at wavelengths shorter than $330 \mathrm{~nm}$ to troposheric aerosol is low due to absorption by ozone and due to Rayleigh scattering. Therefore, wavelengths shorter than $330 \mathrm{~nm}$ are not useful for the retrieval of tropospheric aerosol. The wavelength bands are about $1 \mathrm{~nm}$ wide and are chosen such that the reflectance spectrum within the bands is essentially free from molecular absorption and strong Raman features. The impact of scattering and absorption by aerosol on the measured reflectance in the chosen wavelength bands is spectrally smooth. The aerosol optical thickness is retrieved using a non-linear least squares fitting routine for a set of aerosol models. The algorithm provides also the single-scattering albedo of the aerosol model that fits best the spectral reflectance measurement. The aerosol models differ in terms of refractive index, size distribution, and height of the aerosol layer. Synthetic reflectance data are stored in a Look-Up Table (LUT) allowing efficient forward simulations for a broad range of aerosol models.

A priori data for the surface albedo spectrum are used in the retrieval scheme and a cloud screening scheme is applied in order to exclude cloud contaminated scenes from the retrieval. Aerosol retrieval from OMI measurements is difficult since the measured spectra do not contain sufficient information to determine all relevant aerosol parameters independently, even when the surface albedo is known accurately and the presence of clouds can be excluded. Therefore, a priori knowledge about the seasonal and spatial distribution of aerosol types is used in order to constrain the retrieval. An assessment of this information content is thus essential for choosing constraints and for estimating the reliability of retrieved aerosol parameters.

In this study we investigate the information content of OMI reflectance measurements in the wavelength bands used in the multi-wavelength aerosol algorithm. The number of Degrees of Freedom of the Signal (DFS) is quantified by applying a Principal Component Analysis (PCA, Sect. 2) to synthetic reflectance spectra for a large number of scenarios with various aerosol models, observation geometries and surface types. About 250 aerosol models for biomass burning, desert dust, and weakly absorbing aerosol are taken into account with a wide range of aerosol optical thicknesses, layer altitudes, refractive indices and size distributions (Sect. 3). As compared to using real measurements, using synthetic data has the advantage that aerosol parameters can be controlled and that cloud effects can be controlled or excluded. The results of the principal component analysis are immediately applicable to the multi-wavelength algorithm, since the
PCA is applied to the synthetic reflectance data stored in the aforementioned LUT. The results of the PCA depend on the aerosol parameter ranges covered by the set of aerosol models considered. The basic assumption made in this study is that the aerosol models cover the natural variability of atmospheric aerosol. The number of DFS obtained from the PCA is representative for the number of aerosol parameters that can be retrieved independently from OMI reflectance measurements provided that the surface albedo spectrum is accurately known and the presence of clouds can be completely excluded. In practice, the multi-wavelength algorithm relies on cloud data from an operational OMI product and on apriori data for the surface albedo spectrum from climatologies. Such surface albedo climatologies have been generated based on TOMS data (Herman and Celarier, 1997; Herman et al., 2001) GOME data (Koelemeijer et al., 2003) and MODIS data (Vermote and Vermeulen, 1999). A dedicated sensitivity study has been performed to assess the impact of errors in the surface albedo spectrum on the aerosol retrieval. The presence of undetected clouds cannot be excluded completely and is a possible source of errors in the aerosol retrieval scheme. Cloud models (ice clouds and water clouds) are included in the analysis in order to investigate whether the spectral information used in the multi-wavelength algorithm can be used to distinguish clouds from aerosols and how the algorithm behaves when clouds are present.

An additional wavelength band is included in the analysis comprising the absorption band of the $\mathrm{O}_{2}-\mathrm{O}_{2}$ collision complex at $477 \mathrm{~nm}$. This absorption band is used for the retrieval of the cloud height from OMI reflectance measurements (Acarreta and de Haan, 2002; Acarreta et al., 2004). For a cloud-free atmosphere the depth of the $\mathrm{O}_{2}-\mathrm{O}_{2}$ absorption band gives the effective scattering height of the atmosphere, which is different for an aerosol-loaded atmosphere than for an aerosol-free atmosphere. This sensitivity is pronounced especially at low altitudes since the vertical distribution of $\mathrm{O}_{2}-\mathrm{O}_{2}$, being proportional to the square of the pressure, is strongly peaked over the ground. Therefore, it is expected that the multi-wavelength algorithm provides information about the altitude of aerosol layers with a sufficiently high AOT when the wavelength band at $477 \mathrm{~nm}$ is included.

In Sect. 4 the number of DFS of OMI reflectance measurements is discussed for several different surface albedo spectra and observation geometries. We quantify the importance of including the wavelength bands in the UV and estimate how much information is added when the wavelength band at $477 \mathrm{~nm}$ is included in the multi-wavelength algorithm. The weights associated with the principal components provide a graphical view on the aerosol retrieval. This concept is used to investigate the cross correlations of the retrieved aerosol parameters such as AOT, SSA, aerosol layer altitude and particle size. The multi-wavelength aerosol retrieval algorithm is assessed regarding its capability to distinguish various aerosol types and to discern high cirrus clouds and low water clouds from aerosols. 


\section{Principal Component Analysis}

The Principal Component Analysis (PCA) (cf. Jolliffe, 1986; Tanré, 1996) is applied to determine the number of Degrees of Freedom of Signal (DFS) of OMI reflectance measurements. The DFS that are associated with aerosol parameters are quantified by applying the PCA to synthetic reflectance data in the wavelength bands used in the multi-wavelength aerosol retrieval. These synthetic reflectance data are based on radiative transfer simulations for scenarios with variable aerosol parameters. The obtained number of DFS is interpreted as the number of aerosol parameters that can be extracted from real OMI reflectance measurements in cloudfree cases with a known surface albedo spectrum.

The PCA works as follows: The set of $m$ reflectance measurements is stored in the measurement matrix $\mathbf{R}$ with the elements $R_{l m}$ where the column vectors are the $m$ reflectance vectors and the index $l$ indicates the wavelength band. The measurement matrix $\mathbf{R}$ is standardized such that for each wavelength, the mean value of all measurements is zero and the standard deviation is unity. The covariance matrix $\mathbf{A}=\mathbf{R R}^{T}$ is diagonalized according to

$\mathbf{A}=\mathbf{V}^{T} \mathbf{D V}$

such that the row vectors of the matrix $\mathbf{V}$ form an orthonormal set of $K$ eigenvectors and that the eigenvalues $\gamma_{k}$ on the diagonal of the matrix $\mathbf{D}$ are sorted in descending order. The eigenvectors are referred to as the Principal Components (PC) of the measurement. Each reflectance measurement can be decomposed into a weighted sum of principal components viz.

$R_{l m}=\hat{R}_{l m}+\varepsilon=\sum_{k}^{k_{\max }} W_{m k} V_{k l}+\varepsilon$,

where $\hat{R}_{l m}$ are the elements of the reconstructed measurement matrix with an error $\varepsilon$. This can be written compactly in matrix notation as $\mathbf{R}=\mathbf{V}^{T} \mathbf{W}$ with $W_{m k}$ being the elements of the matrix $\mathbf{W}$. The weights $W_{m k}$ are determined by the linear transformation $\mathbf{W}=\mathbf{V R}$ which projects each measurement vector on each PC. In the following, the index $m$ will be omitted for convenience when the weights are referred to. The matrix $\mathbf{V}$ transforms the measurement matrix $\mathbf{R}$ into the space of weights with the principal components as basis vectors.

The eigenvalue $\gamma_{k}$ is the variance of the weights $W_{k}$ of all $m$ measurements for a given order $k$. Due to the standardization the weights are scattered around zero. Therefore the eigenvalue $\gamma_{k}$ is a measure for the importance of the principal component of the order $k$. The principal components are ordered in descending order of importance.

Naturally, when a measurement is reconstructed using all $K$ principal components $\left(k_{\max }=K\right.$ in Eq. 3$)$, the error $\varepsilon$ is zero. The sum in Eq. (3) can be truncated at $k_{\max }<K$ without any loss of information as long as the error $\varepsilon$ is smaller than the error due to instrument noise. We define the error $\Psi_{m}$ of the reconstructed reflectance measurements viz. (see Tanré et al., 1996)

$\Psi_{m}=\left[\frac{1}{(N-1)} \sum_{l}^{N}\left(\frac{\hat{R}_{l m}-R_{l m}}{R_{l m}}\right)^{2}\right]^{1 / 2}$,

where $N$ is the number of wavelengths. This reconstruction error is compared to an equivalent error $\Psi_{\text {noise }}$ associated with instrument noise assuming a Signal to Noise Ratio (SNR) of 1000. This is a typical value for OMI reflectance measurements in the UV. The SNR of OMI reflectance measurements in the visible ranges between 1000 and 1500 (Levelt et al., 2006b). Principal components that are necessary to reconstruct a given measurement $R$ up to an error $\Psi_{m}<\Psi_{\text {noise }}$ are considered significant. The number of DFS is identified with the number of significant PC.

Summing up, we note that the PCA provides an ordered series of principal components forming an ortho-normal set of basis-vectors that capture the variability of all measurements considered. The eigenvalue of the order $k$ is a measure for the importance of the PC of the same order for reconstructing the variability of all measurement vectors. The number of degrees of freedom of the signal is specific to individual reflectance measurement and is derived from reconstructing individual reflectance measurements with errors below a given noise threshold. The PCA provides a transformation of the observation space to a new coordinate system with the principal components as basis functions. The number of dimensions of this new parameter space is reduced to the number of DFS.

\section{Synthetic reflectance data}

A large number of synthetic reflectance spectra is used in the PCA. Radiative transfer simulations are based on a Look-Up Table (LUT) that includes simulations for a many different aerosol models for various aerosol types including biomass burning, desert dust, weakly absorbing and volcanic aerosols. The aerosol models cover a range of microphysical parameters including the wavelength-dependent complex refractive index and the size distribution, as well as a range of atmospheric scenarios with varying AOT and aerosol layer altitudes. The size distribution and the refractive index of the aerosol models are listed in Table 2. Aerosol layer altitudes of 1,3 and $5 \mathrm{~km}$ are considered for biomass burning and desert dust aerosol. A layer altitude of $1 \mathrm{~km}$ is assumed for the models for weakly absorbing aerosols. The AOT varies between 0 and an upper limit that takes values of $2.5,5$ or 10 for weakly absorbing, biomass burning or desert dust aerosol respectively. AOT values are given in terms of the AOT at the reference wavelength of $500 \mathrm{~nm}$, throughout this article. With the range of refractive indices considered, the SSA of the aerosol ranges between 0.8 and 1 . Various bimodal size 
Table 2. Size distribution and refractive index of OMI aerosol models. The major aerosol types, weakly absorbing aerosol (WA), biomass burning aerosol (BB) and desert dust (DD), are divided into sub-types according to size distribution, refractive index, and vertical distribution. Mean radii $r_{g}$ and variances $\sigma$ of log-normal number distributions are listed for the modes $\mathrm{m} 1$ and $\mathrm{m} 2$ of bimodal size distributions together with the particle number fraction of the second mode. The imaginary part of the refractive index of desert dust is wavelength-dependent and takes values up to $1.69 \mathrm{E}-3\left(^{*}\right)$ or $0.013\left(^{\#}\right)$ in the UV. Models for water clouds $(\mathrm{CW})$ and for ice clouds $(\mathrm{CI})$ are included. The shape of the ice crystals are modelled using imperfect hexagonal prisms large compared to the wavelength.

\begin{tabular}{lccccccl}
\hline Model & $r_{g} \mathrm{~m} 1$ & $r_{g} \mathrm{~m} 2$ & $\sigma \mathrm{m} 1$ & $\sigma \mathrm{m} 2$ & fraction & real & imag \\
\hline WA_1101 & 0.078 & 0.497 & 1.499 & 2.160 & $4.36 \mathrm{e}-4$ & 1.4 & $5.0 \mathrm{e}-8$ \\
WA_1102 & 0.088 & 0.509 & 1.499 & 2.160 & $4.04 \mathrm{e}-4$ & 1.4 & $5.0 \mathrm{e}-8$ \\
WA_1103 & 0.137 & 0.567 & 1.499 & 2.160 & $8.10 \mathrm{e}-4$ & 1.4 & $5.0 \mathrm{e}-8$ \\
WA_1201 & 0.078 & 0.497 & 1.499 & 2.160 & $4.36 \mathrm{e}-4$ & 1.4 & 0.004 \\
WA_1202 & 0.088 & 0.509 & 1.499 & 2.160 & $4.04 \mathrm{e}-4$ & 1.4 & 0.004 \\
WA_1203 & 0.137 & 0.567 & 1.499 & 2.160 & $8.10 \mathrm{e}-4$ & 1.4 & 0.004 \\
WA_1303 & 0.085 & 0.641 & 1.560 & 2.004 & $7.00 \mathrm{e}-4$ & 1.45 & 0.012 \\
WA_1301 & 0.090 & 0.676 & 1.560 & 2.004 & $6.84 \mathrm{e}-4$ & 1.45 & 0.012 \\
WA_1302 & 0.109 & 0.804 & 1.560 & 2.004 & $6.95 \mathrm{e}-4$ & 1.45 & 0.012 \\
BB_2101 & 0.074 & 0.511 & 1.537 & 2.203 & $1.70 \mathrm{e}-4$ & 1.5 & 0.010 \\
BB_2102 & 0.087 & 0.567 & 1.537 & 2.203 & $2.06 \mathrm{e}-4$ & 1.5 & 0.010 \\
BB_2103 & 0.124 & 0.719 & 1.537 & 2.203 & $2.94 \mathrm{e}-4$ & 1.5 & 0.010 \\
BB_2201 & 0.076 & 0.665 & 1.492 & 2.075 & $2.07 \mathrm{e}-4$ & 1.5 & 0.020 \\
BB_2202 & 0.080 & 0.705 & 1.492 & 2.075 & $2.05 \mathrm{e}-4$ & 1.5 & 0.020 \\
BB_2203 & 0.097 & 0.866 & 1.492 & 2.075 & $1.99 \mathrm{e}-4$ & 1.5 & 0.020 \\
BB_2301 & 0.074 & 0.511 & 1.537 & 2.203 & $1.70 \mathrm{e}-4$ & 1.5 & 0.030 \\
BB_2302 & 0.087 & 0.567 & 1.537 & 2.203 & $2.06 \mathrm{e}-4$ & 1.5 & 0.030 \\
BB_2303 & 0.124 & 0.719 & 1.537 & 2.203 & $2.94 \mathrm{e}-4$ & 1.5 & 0.030 \\
DD_3101 & 0.042 & 0.670 & 1.697 & 1.806 & $4.35 \mathrm{e}-3$ & 1.53 & $\lambda-$ dep.* \\
DD_3102 & 0.052 & 0.670 & 1.697 & 1.806 & $4.35 \mathrm{e}-3$ & 1.53 & $\lambda-$ dep.* \\
DD_3201 & 0.042 & 0.670 & 1.697 & 1.806 & $4.35 \mathrm{e}-3$ & 1.53 & $\lambda-$ dep.\# \\
DD_3202 & 0.052 & 0.670 & 1.697 & 1.806 & $4.35 \mathrm{e}-3$ & 1.53 & $\lambda-$ dep. \\
CI_5000 & $\gg \lambda$ & - & - & - & - & 1.31 & $0.19 \mathrm{e}-07$ \\
CW_6000 & 6.0 & - & 0.111 & - & - & 1.34 & 0 \\
\hline
\end{tabular}

distributions are included defined by lognormal number distributions (for definition see Hansen and Travis, 1974). It is assumed that the range of aerosol parameters is representative for the natural variability of aerosol.

The values and ranges of the aerosol parameters of the aerosol models are mainly based on the set of aerosol models discussed in Torres et al. (2002b). The parameters of these models have been chosen based on, amongst others, longterm Aerosol Robotic Network (AERONET) sun-photometer observations (Holben et al., 1998) such as the study by Dubovik et al. (2002) for biomass burning, desert dust, and urban-industrial aerosol. Values for the wavelengthdependent imaginary part of the refractive index of desert dust aerosol have been taken from Sinyuk et al. (1993). A model for stratospheric volcanic aerosol is characterized using data from Bauman (2000). As compared to the models defined by Torres et al. (2002b) the upper limit of the aerosol optical depth (AOT) of desert dust has been extended to 10 in order to account for intense dust storms directly at the source. The impact of the choice of the AOT range on the results of the PCA analysis is discussed in Sect. 4.2. Models for strongly absorbing desert dust have been included in order to account for the variability in terms of the absorption. The imaginary part of the refractive index of these models is an average of the values reported by Sinyuk et al. (1993) and the high values reported by Patterson et al. (1997). The main aerosol types "urban" and "oceanic" used by Torres et al. (2002b) have been combined to the main type "weakly absorbing". This choice has been made based on what can be distinguished by the OMI instrument.

Altogether, about 250 aerosol models are taken into account. In the framework of the present study the LUT has been extended by the additional wavelength band at $477 \mathrm{~nm}$ and by cloud models for ice-clouds and water clouds (see Table 2). The first cloud model represents ice clouds consisting of imperfect hexagonal prisms large compared to the wavelength (with linear dimensions larger than $25 \mu \mathrm{m}$ ) (Hess et al., 1998; Knap et al., 1998). The ice cloud layer has an altitude of $10 \mathrm{~km}$. The second cloud model (model C1 (Deirmendjian, 1969)) represents water clouds consisting of spherical particles at an altitude of about $2.5 \mathrm{~km}$. 


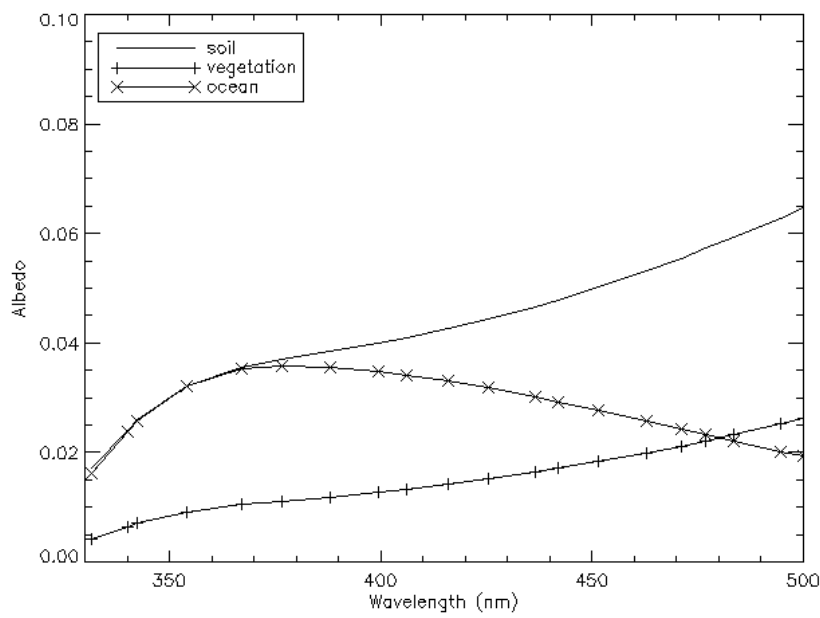

Fig. 2. Surface albedo spectra for soil, vegetation and ocean used in the PCA.

Single-scattering properties of all aerosols types have been simulated using Mie-theory assuming spherical particles (Van de Hulst, 1957). The irregular shapes of desert dust particles is not taken into account in this study. The phase function predicted by Mie theory overestimates the phase function of irregular dust particles at scattering angles close to the backward scattering direction and underestimates the phase function at sideward scattering angles (Volten et al., 2001). The cross section of scattering and absorption of irregularly shaped particles with sizes comparable to the wavelength are overestimated by Mie theory. For singleviewing instruments such as OMI, this can cause biases in the retrieved aerosol parameters such as AOT (Mishchenko et al., 1995; Masuda et al., 2002) and SSA (Veihelmann et al., 2004). Scaling effects in the reflectance spectra related to the deviation of cross sections and the phase functions of mineral dust from the Mie prediction are small compared to the scaling effects due to the variability of AOT and SSA of the models used for the PCA. Therefore the number of DFS is not affected significantly by the spherical shape approximation. The impact of non-sphericity on the results of the present analysis concerning individual desert dust models is small if the shape effect on the aerosol optical characteristics is small compared to the effect of the strong absorption of mineral dust in the UV. Since this absorption in the UV is a very prominent characteristic of mineral dust, we assume that the results of the present analysis provides a good indication for the way the multi-wavelength algorithm treats non-spherical desert dust aerosol. We note that it is envisaged to generate aerosol models for desert dust taking into account particle non-sphericity. Hereby the irregular shaped particles will be approximated by an ensemble of randomly oriented spheroids.

Optical properties of an atmosphere containing aerosol are computed with the DAK program (Doubling-Adding KNMI)

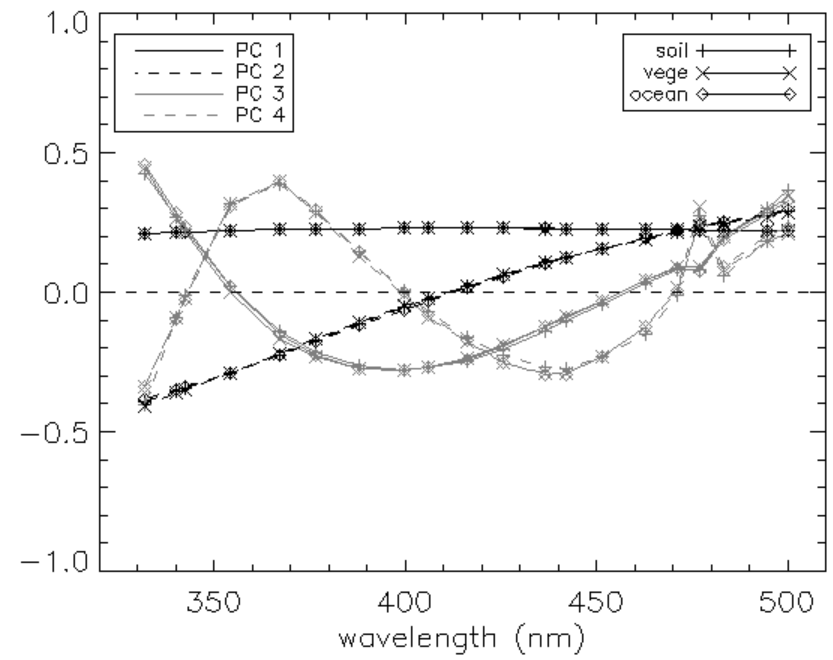

Fig. 3. Principal components for typical albedo spectra of soil (+), vegetation $(x)$ and an ocean surface (diamonds). The first (solid black), second (dashed black), third (solid grey) and fourth component (dashed grey) are depicted as a function of the wavelength.

(de Haan et al., 1987; Stammes et al., 1989; Stammes, 2001). The results of the radiative transfer simulations are stored in the LUT for all wavelengths $\lambda$ used in the multiwavelength algorithm in terms of the path radiance $R_{p}$, the surface albedo spectrum $a$, the spherical albedo of the atmospheric for illumination from below $S$, as well as the atmospheric transmission $T$. The reflectance $R$ at the top of the atmosphere can be evaluated very fast using (Chandrasekhar, 1960)

$$
\begin{aligned}
R\left(\lambda, \mu, \mu_{0}, \Delta \phi, p_{s}\right)= & R_{p}\left(\lambda, \mu, \mu_{0}, \Delta \phi, p_{s}\right) \\
& +\frac{a(\lambda) T\left(\lambda, \mu, \mu_{0}, p_{s}\right)}{1-a(\lambda) S\left(\lambda, p_{s}\right)}
\end{aligned}
$$

for any given scenario with a geometry defined by the cosines of the solar zenith angle $\mu_{0}=\cos \left(\theta_{S}\right)$ and the viewing zenith angle $\mu=\cos \left(\theta_{v}\right)$ and the relative azimuth angle $\Delta \phi$, the surface albedo $a$ and the terrain height expressed in terms of the ground pressure $p_{s}$. The relative azimuth angle $\phi$ is defined such that the sun-glint is observed at $\Delta \phi=0^{\circ}$ for $\theta_{s}=\theta_{v}$. The synthetic reflectance data used in the PCA are calculated for a given geometry using many different aerosol models and a constant surface albedo spectrum $a(\lambda)$ that is typical for ocean, vegetation or soil (see Fig. 2).

\section{Results}

In this section the results of the PCA are discussed for a large number of scenarios. The capabilities of the multiwavelength algorithm are assessed using the number of DFS as well as the weights of the principal components. Special attention is paid to clouds and to errors in the surface albedo spectrum. 


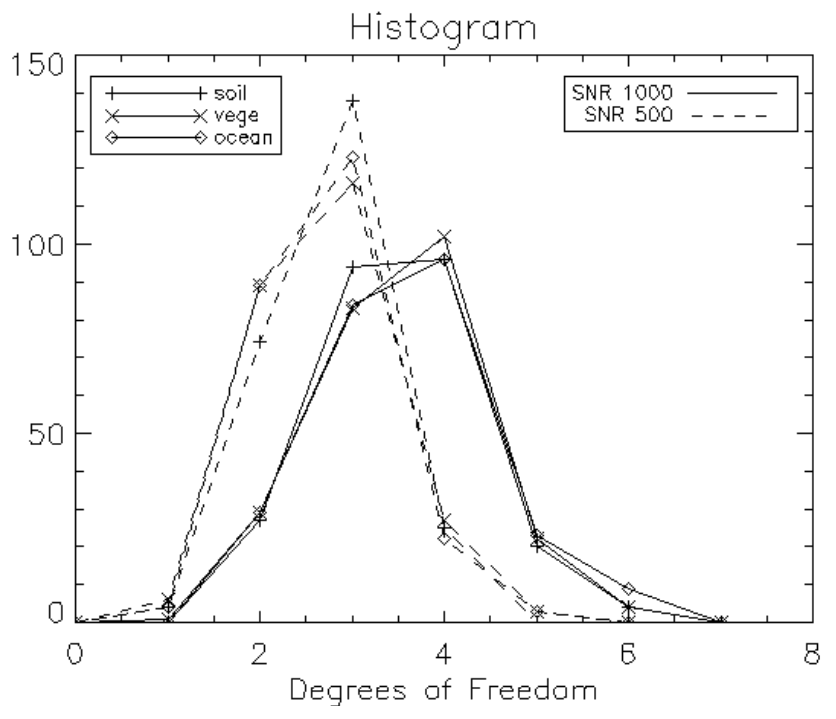

Fig. 4. Histogram of the number of DFS of OMI reflectance measurements for 250 aerosol models for soil $(+)$, vegetation $(x)$ and ocean surface (diamonds) using a noise threshold corresponding to a signal to noise ratio of 500 (dashed) and 1000 (solid).

\subsection{Principal components}

The set of principal components obtained from the PCA is largely independent from the surface albedo spectrum. Figure 3 shows the first four principal components for surface albedo spectra of ocean $(+)$, soil $(*)$, and vegetation (diamonds) for a typical observation geometry with a solar zenith angle $\theta_{s}=53^{\circ}$, a viewing zenith angle $\theta_{v}=26^{\circ}$, and a relative azimuth $\Delta \phi=30^{\circ}$. The first PC is nearly constant for all wavelength bands and therefore controls the global level of the reflectance. The second component controls the slope of the reflectance as a function of the wavelength. Higher order components capture "slow" variations of the reflectance spectrum as well as the absorption feature at $477 \mathrm{~nm}$. When more than the first and the second $\mathrm{PC}$ are required for reconstructing a measurement, the $477 \mathrm{~nm}$ band becomes important. Although the principal components in general depend on the observation geometry, the amplitudes and overall shapes of the components of other geometries resemble the graphs shown in Fig. 3.

\subsection{Number of degrees of freedom of signal}

The eigenvalues (and hence also the weights associated with the principal components) drop fast with increasing order: for most geometries and surface types, more than $80 \%$ of the reflectance measurements can be reproduced within the measurement error when including 2 to 4 PC; Principal components of higher orders are not relevant for most models since their contribution to the reflectance is dominated by instrument noise.

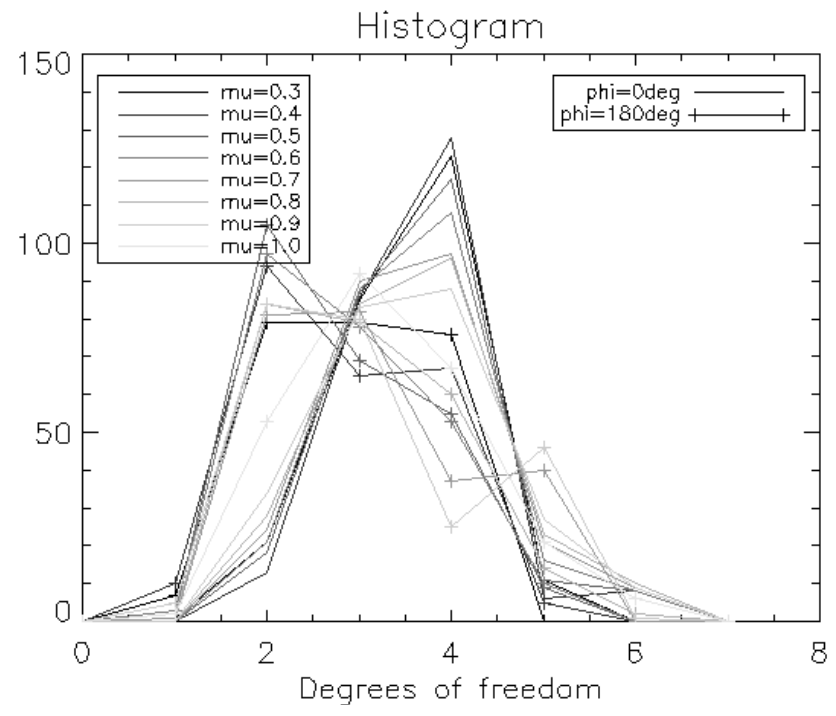

Fig. 5. Histogram of the number of DFS of OMI reflectance measurements for 250 aerosol models, various viewing zenith angles $\theta_{v}$ referred to as $\mu=\cos \left(\theta_{v}\right)$ in the legend (grey scales), and relative azimuth angles of $0^{\circ}$ (no marker) and $180^{\circ}(+)$. The solar zenith angle is $53^{\circ}$.

The number of DFS calculated as explained in the previous section depends on the observation geometry, the surface albedo and the choice of the noise threshold. In order to give an overview of the information content of OMI reflectance measurements we show histograms of the number of DFS of all aerosol models considered for various scenarios. In Fig. 4 the histogram of the number of DFS is plotted for the observation geometry with $\theta_{s}=53^{\circ}, \theta_{v}=26^{\circ}, \Delta \phi=30^{\circ}$ and surface albedo spectra for soil $(+)$, vegetation $(\times)$ and ocean (diamonds). When a SNR of 1000 is assumed for the error threshold $\Psi_{\text {noise }}$, we obtain 3 or 4 degrees of freedom for most of the aerosol models (solid lines). When this noise criterion is relaxed by assuming a lower SNR (with a value of 500), 2 or 3 degrees of freedom are sufficient to reproduce most of the aerosol models (dashed lines). This may be a conservative estimate for the number of DFS taking into account possible error contributions that are not represented by the instrument noise characterization but nevertheless introduce random-like structures in the reflectance measurement. Figure 4 shows that the number of DFS does not depend critically on the surface albedo spectrum.

The geometry dependence of the number of DFS is depicted in Fig. 5. Histograms for the number of DFS of all aerosol models are shown for a series of geometries with viewing angles ranging from $\theta_{v}=73^{\circ}$ (black) to $\theta_{v}=0^{\circ}$ (light grey), relative azimuth angles $\Delta \phi=0^{\circ}$ (no symbols) and $\Delta \phi=180^{\circ}(+)$ and a solar zenith angle of $\theta_{s}=53^{\circ}$. A SNR of 1000 is used for the noise threshold. The information content of OMI reflectance measurements tends to be higher for geometries with $\Delta \phi=0^{\circ}$ than for geometries with $\Delta \phi=180^{\circ}$. 


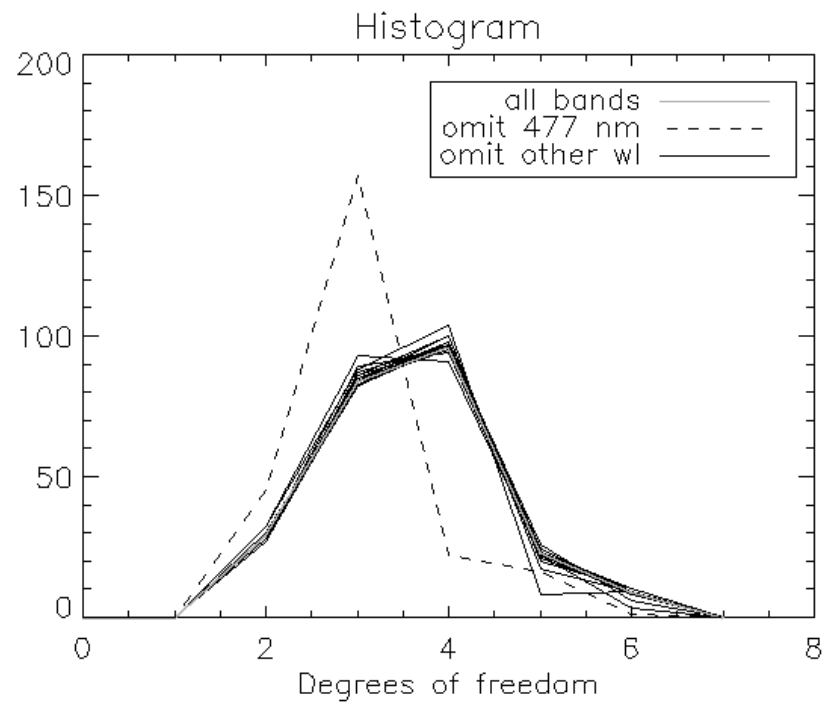

Fig. 6. Histogram of the number of DFS of OMI reflectance measurements for 250 aerosol models for a case where all wavelength bands are included (solid grey), a case where the $477 \mathrm{~nm}$ band is omitted (dashed black), and cases where other wavelength bands are omitted (solid black).

This may be related to the fact that in the latter geometries, the signal is stronger influenced by Rayleigh scattering. In most cases the number of DFS varies between 2 and 4 .

In the set of models used for the PCA the AOT takes values up to 2.5 (weakly absorbing), 5.0 (biomass burning) or 10.0 (desert dust). Values of 2.5 and larger are observed in the lee of desert during dust outbreak events. Globally, however, the frequency of occurrence of such high AOT is low. Hence, the choice of the upper boundary of the AOT variation is arbitrary to a certain extent. An additional PCA is performed on a reduced dataset based on aerosol models with a maximum AOT of 2.5. As compared to the nominal case, the average number of DFS becomes smaller by about 0.2 for all surface types considered. This decrease is small compared to the total number of DFS. Hence, we conclude that the choice of the upper boundary of the AOT variation is not critical for the results of the present study.

\subsection{Wavelength bands}

The relative importance of the individual wavelength bands is investigated by performing PCA repeatedly on reduced reflectance data where one wavelength band is omitted. Figure 6 shows a comparison of the nominal case where all wavelength-bands are included (light grey) with one case where the $477 \mathrm{~nm}$ band is omitted (dashed) and with other cases where other wavelength bands are omitted (black). The observation geometry $\theta_{s}=53^{\circ}, \theta_{v}=26^{\circ}, \Delta \phi=30^{\circ}$ and a typical surface albedo spectrum of soil is chosen. The noise threshold is based on a SNR of 1000. This comparison shows that the wavelength band at $477 \mathrm{~nm}$ adds more information

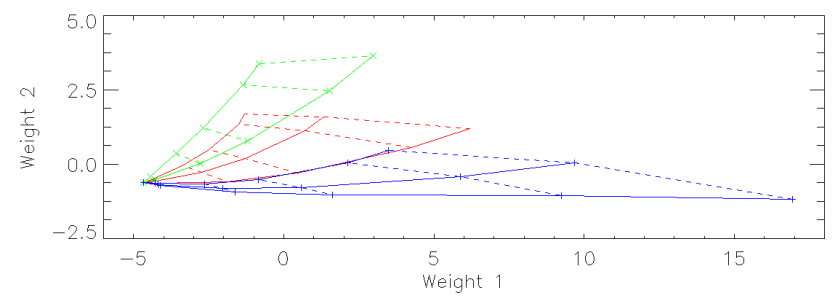

Fig. 7. Weights of the first and second component for models for biomass burning (red, no markers), desert dust (green, $\times$ ) and weakly absorbing (blue, + ) aerosols. Solid lines connect models with a variable aerosol optical thickness ranging from 0 to 5 , while all other parameters are constant. Dashed lines connect models with a variable single scattering albedo.

than any other individual wavelength band. Excluding any of the nominal wavelength bands has essentially no impact on the information content.

Furthermore, we find that the number of DFS remains nearly constant when up to 10 of the nominal wavelength bands are excluded such that the remaining bands are evenly distributed over the total wavelength range (from $331 \mathrm{~nm}$ to $500 \mathrm{~nm}$ ). Hence, the nominal wavelength bands contain redundant information. Nevertheless increasing the number of wavelength bands reduces errors due to noise. Note that this is not reflected by the number of DFS derived in this study as can be seen from the definition of the reconstruction error (see Eq. 4): this error as well as the threshold value applied is independent from the number of wavelength bands when a large number of bands with the same SNR is considered. When all 8 wavelength bands below $400 \mathrm{~nm}$ are excluded, about one DFS is lost. This highlights the importance of the wavelength bands in the UV for the aerosol retrieval.

\subsection{Separation of aerosol parameters}

The distribution of aerosol models in the space of weights is employed in order to investigate whether aerosol parameters can be separated in the aerosol retrieval using the multiwavelength algorithm. Figure 7 shows the variation of the SSA and the AOT in the space of the first two weights for biomass burning (red, no markers), desert dust (green, $\times$ ) and weakly absorbing aerosols (blue, + ). Solid lines connect models with a variable aerosol optical thickness ranging from 0 to 5, while all other parameters are constant. Dashed lines connect models with a variable single scattering albedo. The range of the SSA depends on the aerosol type (e.g. 0.82 to 0.94 for biomass burning aerosols, see Table 2). For clarity, only models with one constant layer altitude and one aerosol size are shown. The weights are plotted with the same scale. When the solid and the dashed lines in this plot intersect at a right angle, the retrieved values of AOT and SSA for a given measurement are uncorrelated provided that at least two DFS can be associated with aerosol parameters. The correlation 

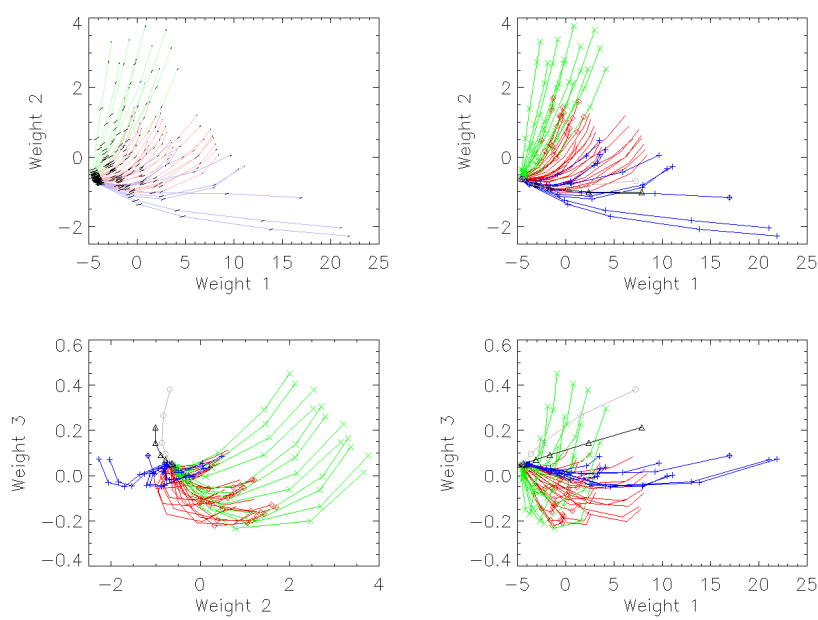

Fig. 8. Weights of the models for biomass burning (red, no markers), desert dust (green, $\times$ ) and weakly absorbing (blue, + ) aerosols as well as for high ice clouds (black triangles) and low water clouds (grey circles). Models with the same parameters but with a varying optical thickness are connected with solid lines. The upper left panel shows the deviation of the weights upon a variation of the surface albedo of \pm 0.01 (black solid lines).

of the retrieved values of AOT and SSA becomes more pronounced when the inscribed angle decreases. AOT and SSA can be separated in the retrieval when the mutual correlation is weak and the weights are sufficiently sensitivity to both parameters. It appears that the AOT and the SSA can be rather well separated in most cases. For aerosols with a low absorption, the retrieved values of AOT and SSA are somewhat correlated. Nevertheless the large separation of the models for weakly absorbing aerosols in the space of weights indicates a strong sensitivity of the reflectivity signal to both parameters.

The mutual correlations between other retrieved aerosol parameters have been investigated using graphs (not shown) similar to the one shown in Fig. 7. It appears that both the layer altitude and the particle size are rather well separable from the AOT in most cases. If only two DFS are available, retrieved values of the SSA are strongly correlated with retrieved values of both the layer altitude and the particle size. When three or more DFS are available, our results indicate pronounced correlations of the particle size with the SSA; at the same time the SSA and the layer height appear to be separable in many cases especially when desert dust is present.

\subsection{Distinction of aerosol types}

The capability of the multi-wavelength algorithm to discern aerosol types is investigated using the distribution of the models in the space of weights of the PC. Figures 8 and 9 show the weights of the first three components $W_{1}, W_{2}$ and $W_{3}$ of all models for biomass burning (red, no markers), desert dust (green, $\times$ ) and weakly absorbing aerosols (blue, + ). In Fig. 9 the weights are depicted in a 3-dimensional

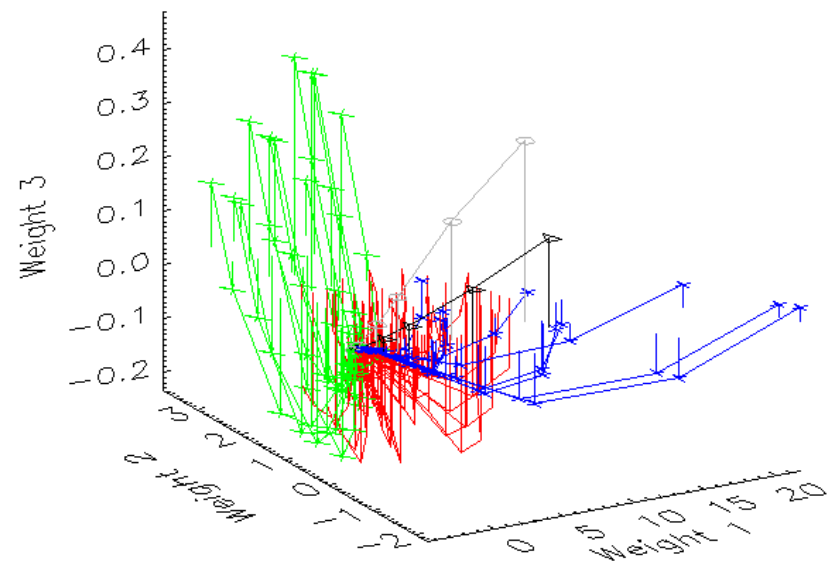

Fig. 9. Weights of the first three principal components of all aerosol and cloud models in a 3-dimensional scatter-plot (for assignment of colours and markers see caption Fig. 8). Vertical lines are a guide for the eye and connect the markers with the horizontal plane defined by the weight of the third component for the case that aerosols and clouds are absent.

scatter-plot. The vertical bars in Fig. 9 are a guide for the eye and connect the symbols with the horizontal plane with the weight of the third PC of the case with AOT=0. Models with the same aerosol parameters but with a varying AOT are connected with solid lines. Figure 8 shows projections of the 3-dimensional scatter-plot along each one of the coordinate axes respectively. Such plots have been investigated for various typical observation geometries and various surface albedo spectra. In Figs. 8 and 9 we show results for cases with a geometry defined by $\theta_{s}=53^{\circ}, \theta_{v}=26^{\circ}, \Delta \phi=30^{\circ}$, and with an ocean surface, while the wavelength band at $477 \mathrm{~nm}$ is included.

The weights $W_{1}$ and $W_{2}$ (upper right panel of Fig. 8) indicate, whether aerosol models can be discerned or not, for cases where only two DFS are available. Here, models for different aerosol types appear in rather well defined for AOT values of 0.5 and larger. The domain of biomass burning aerosols overlaps with both the domains of desert dust and weakly absorbing aerosols. The overlap regime with the domain of desert dust models comprises predominantly models for strongly absorbing biomass burning aerosols. This overlap is less pronounced for scenes observed in the western part of the swath. When desert dust is mistakenly classified as biomass burning aerosol the AOT is overestimated. The overlap regime of the domain of biomass burning aerosols with the domain for weakly absorbing aerosol comprises models with very similar aerosol parameters. This includes models for biomass burning aerosols with the lowest absorption $(\mathrm{m}=1.5-0.01 \mathrm{i})$ and weakly absorbing aerosols with the highest absorption $(\mathrm{m}=1.4-0.012 \mathrm{i})$ at a layer altitude of $1 \mathrm{~km}$. Aerosol models of these types can be distinguished in the aerosol retrieval if their imaginary part of the refractive index differs by about 0.1 or more or if the layer altitude differs 
by $1 \mathrm{~km}$ or more. Desert dust and weakly absorbing aerosols can be well distinguished except for very low values of the AOT.

If three DFS are available, the weights $W_{1}, W_{2}$ and $W_{3}$ have to be taken into account in order to decide, whether aerosol models can be discerned or not. Some of the models that appear in an overlap regime in the upper right panel of Fig. 8 can be assigned to one aerosol type based on the third weight $W_{3}$ (lower panels in Fig. 8). Models for biomass burning aerosol that fall in the domain of desert dust models in the 3-dimensional space of weights are marked with red diamonds. In the space of the weights $W_{2}$ and $W_{3}$ (lower left panel), the overlap of the regimes appears more pronounced when a scene is observed with a high viewing zenith angles $\left(\theta_{v}>30^{\circ}\right)$ in the western part of the swath (toward the sun), whereas no overlap is found in various cases where a scene is observed with a high viewing zenith angles $\left(\theta_{v}>30^{\circ}\right)$ in the eastern part of the swath (away from the sun). Figure 8 shows an intermediate case with a moderate overlap which is also typical for nadir observation geometries.

\subsection{Surface albedo}

The multi-wavelength aerosol retrieval requires a-priori information about the surface albedo spectrum since it is not possible to discern signatures due to the surface albedo spectrum from signatures due to aerosols in OMI reflectance measurements. A PCA has been performed to extended sets of synthetic reflectance measurements where a variability of the surface albedo spectrum is included by means of an additional free parameter. In one case a variable wavelengthindependent term is added to the surface albedo spectrum of an ocean surface. In another case the surface albedo spectra of soil and vegetation are mixed with a variable weight ranging from 0 (pure soil) to 1 (pure vegetation). We observe that the number of DFS does not increase as compared to cases where the surface albedo spectrum is fixed. This confirms that the surface albedo spectrum cannot be retrieved independently from aerosols parameters using OMI reflectance measurements.

The surface albedo data used in the aerosol retrieval is taken from a climatology and may deviate from the true surface albedo spectrum of a given scenario. In order to estimate the impact of such errors on the aerosol retrieval the surface albedo is varied by \pm 0.01 (at all wavelengths simultaneously) for an aerosol laden atmosphere over an ocean surface (Fig. 8 upper left panel). This corresponds to a relative error of up to several tens of percent of the surface albedo in the UV wavelength region. Black solid lines show the variation of the weights of each aerosol model due to this variation. The faintly coloured lines correspond to the coloured lines in the upper right panel and are included for clarity. When the AOT has a value of about 0.1 or lower, the variation of the weights due to the variation in the surface albedo has a similar magnitude as the separation of the models in the space of weights. In this case, an error of 0.01 (absolute value) has a large impact on the all retrieved aerosol parameters. When the AOT is about 0.5 or larger, the impact of such an error in the surface albedo has a minor impact on the retrieved values of the AOT and the SSA. An error of 0.01 in the surface albedo does not affect substantially the capability of the retrieval to distinguish aerosol types: For a given measurement, the choice of the optimal aerosol type will only be affected if the measurement lies in one of the overlap regions discussed in Section 4.5 or if the AOT is lower than 0.5 . Errors in the assumed surface albedo spectrum on the order of 0.01 are typical for ocean and vegetation surfaces and desert dust areas with moderate surface albedo values below 0.07 (see shown in Fig. 2). Larger errors are expected to occur predominantly at very bright scenes in desert regions. Note that the retrieval of aerosol parameters in such regions is very difficult due to the large contribution of surface reflection to the measured reflectance. This study aims at average cases, excluding scenarios with extremely high surface albedo values. Currently in our group the effort is made to generate an improved surface albedo climatology to be used in the multi-wavelength algorithm. The update of this surface albedo climatology is expected to be one of the most important improvements to be made on the retrieval scheme for land scenes.

\subsection{Clouds}

The models for both high ice clouds and low water clouds are well distinguishable from most aerosol models based on the weights $W_{2}$ and $W_{3}$ (lower left panel in Fig. 8) for an optical thickness of about 0.5 or larger. The model for weakly absorbing with the largest particle sizes and an AOT of 5.0, which comes close to the cloud models in this projection (blue diamond in Fig. 8), can be distinguished well from the cloud models when the weight $W_{1}$ is taken into account. For the cloud models, the weight of the third component increases monotonically with increasing optical thickness. In contrast, most aerosol models exhibit a decrease for low values and an increase for high values of the AOT. The signature of clouds differs from aerosols due to the difference in particle size and due to the absence of pronounced absorption features of water and ice in the wavelength region considered. In contrast to scattering by aerosols, scattering by cloud particles is essentially independent from the wavelength. Furthermore, the signature of high ice clouds differs from the signature of low aerosols since Rayleigh scattering above $10 \mathrm{~km}$ is nearly negligible and due to the altitude dependence of the $\mathrm{O}_{2}-\mathrm{O}_{2}$ absorption feature at $477 \mathrm{~nm}$. According to the weights $W_{1}$ and $W_{2}$ (upper left panel), two DFS are not enough to discern clouds from biomass burning aerosols with a low imaginary part of the refractive index $(\sim 0.01)$ and from weakly absorbing aerosols. The results discussed here concerning the capability of the multi-wavelength algorithm to discern clouds from aerosol are representative for a broad 
variety of cases with different observation geometries and surface albedo spectra.

Cloudy scenes are flagged using the results of the OMI cloud product prior to the aerosol retrieval. Scenes with a very low cloud fraction or a very low cloud optical thickness can be erroneously classified as cloud-free. In this case the deviation of the signal of the cloud model from the Rayleigh case may provide an estimate for the impact of the clouds on the signal in the presence of the aerosol. Whether the choice of the optimal aerosol model in the retrieval is influenced by an undetected cloud with an optical thickness of e.g. 0.1, depends strongly on the scenario. For desert dust with an AOT of 1.0 and larger such an undetected cloud has most probably no impact. Note that at $500 \mathrm{~nm}$ a cloud optical thickness of 0.1 corresponds to a retrieved effective cloud fraction of about 0.02 from the OMI cloud product based on $\mathrm{O}_{2}-\mathrm{O}_{2}$ absorption (Acarreta, 2002). In other cases, when the aerosol models are very close in the space of weights, undetected clouds can cause errors in all retrieved aerosol parameters. We note that if only the AOT is affected, the amplitude of the error is on the order of the cloud optical thickness.

\subsection{Retrieval using weights}

We have tested a retrieval scheme that is based on minimizing the residual of the weights of PC. The results of this retrieval scheme are equal to the results of the nominal retrieval scheme (minimizing the residual of the reflectance) since the linear transformation from the space of reflectance values into the space of weights does not add or remove information. Using a LUT of weights, rather than reflectances, can speed up the aerosol retrieval since the number of the dimensions (the number of wavelength bands) can be reduced to the number of DFS. The number of DFS of an individual OMI reflectance measurement can be determined using the PC obtained from synthetic reflectance data. Hereby, the measurement has to be standardized in the same way as the synthetic data. The number of DFS can be provided as diagnostic output for a given measurement.

\section{Discussion and conclusions}

The information content of OMI reflectance measurements has been investigated using a principal component analysis. The results of this study are applicable to the multiwavelength aerosol algorithm (Torres et al., 2002b). This analysis has been performed on a total of about 250 synthetic OMI reflectance measurements in 20 narrow wavelength bands between $331 \mathrm{~nm}$ to $500 \mathrm{~nm}$. The obtained number of Degrees of Freedom of Signal (DFS) of OMI reflectance measurements varies between 2 and 4 depending on the solar zenith angle, the observation geometry, the instrument noise, the aerosol parameters, and also the surface albedo spectrum. The information content of OMI re- flectance measurements tends to be higher for geometries with $\Delta \phi=0^{\circ}$ than for geometries with $\Delta \phi=180^{\circ}$. This may be related to the fact that in the latter geometries, the signal is stronger influenced by Rayleigh scattering. The number of DFS does not depend critically on the surface albedo spectrum.

The number of DFS reported here are consistent with the results of a theoretical study on the information content of single-viewing satellite observations (Hasekamp and Landgraf, 2005). In that study the DFS is derived from the averaging kernel matrix (Rodgers, 2000). Hasekamp and Landgraf (2005) report that observations using GOME-2 data in 15 wavelength bands between $300 \mathrm{~nm}$ and $800 \mathrm{~nm}$ with a SNR of 2000 contain 3.5 to 5 independent pieces of information when only intensity measurements are evaluated. The number of degrees of freedom found for OMI measurements may be lower because of the narrower wavelength range and the lower SNR (1000 to 1500 in the UV-visible). Also, part of this difference may be due to the fact that different methods have been employed in order to derive the number of DFS. Tanré et al. (1996) report that one to two parameters can be retrieved from observations with MODIS in the wavelength range from $470 \mathrm{~nm}$ to $2130 \mathrm{~nm}$. The relatively large number of DFS found for satellite observations of the solar backscatter in the UV VIS wavelength region is due to the sensitivity of the reflectance to the aerosol layer height, as well as to the fact that the absorption of mineral dust aerosols is wavelength dependent. In this study we have shown that including wavelength bands in the UV at wavelengths below $400 \mathrm{~nm}$ adds about one degree of freedom.

It has been shown that the wavelength band at $477 \mathrm{~nm}$, which comprises an absorption feature of the $\mathrm{O}_{2}-\mathrm{O}_{2}$ collision complex, adds more information than any other individual band. This band becomes important for the retrieval when the number of DFS of OMI reflectance measurements is larger or equal to 3 . The other wavelength bands contain redundant information: up to 10 wavelength bands other than the band at $477 \mathrm{~nm}$ can be excluded without reducing the number of DFS significantly as long as the bands are evenly distributed over the total wavelength range. Hence, it is expected that including more wavelengths bands (additional to the 20 bands taken into account in this study) within the OMI wavelength range can reduce the errors due to noise but will not increase the information content significantly.

The weights of the principal components of all aerosol models have been employed to investigate the capability of the multi-wavelength algorithm to distinguish different aerosol types as well as to distinguish clouds from aerosols. Desert dust aerosol can be discerned from weakly absorbing aerosols when the AOT takes values of about 0.5 or higher. Some models for biomass burning with a high absorption cannot be distinguished from desert dust. Some models for biomass burning with a low absorption cannot be distinguished from weakly absorbing aerosol. This ambiguity depends on the number of DFS and is less pronounced 
if three or more degrees of freedom of the signal can be assigned to aerosol. High ice clouds and low water clouds can be distinguished from most aerosols types when 3 or more degrees of freedom of the signal are available and when the optical thickness takes values of about 0.5 or higher. An efficient cloud screening algorithm is essential for the aerosol retrieval from OMI reflectance measurements especially in background conditions when the AOT takes values of about 0.1 and lower.

The multi-wavelength algorithm relies on a-priori data for the surface albedo spectrum taken from a surface albedo climatology. We have analyzed the impact of an error in the assumed surface albedo spectrum of 0.01 in terms of absolute value, which corresponds to a relative error of up to several tens of percent in the UV wavelength region. We find that such an error in the surface albedo does not affect substantially the capability of the retrieval to distinguish aerosol types: For a given reflectance measurement, the choice of the optimal aerosol type will only be affected if the measurement lies in one of the overlap regions discussed in Sect. 4.5 or if the AOT is lower than 0.5. When the AOT has a value of about 0.1 or lower, an error of 0.01 (absolute value) in the surface albedo has a large impact on the all retrieved aerosol parameters. When the AOT is about 0.5 or larger, the impact of such an error in the surface albedo has a minor impact on the retrieved values of the AOT and the SSA. For an quantitative estimate of the impact on the retrieved SSA we refer to Torres et al. (2002b), who report that an absolute error of 0.01 in the surface albedo can cause an error of 0.01 in the retrieved SSA when OMI reflectance measurements are evaluated using the multi-wavelength algorithm. In $80 \%$ of all cases the error had no impact on the optimal aerosol model chosen by the retrieval (Torres et al., 2002b).

Results indicate that in the retrieval the AOT can be separated rather well from other aerosol parameters such as SSA, layer altitude and particle size. The SSA can be retrieved nearly independently from the AOT if at least two DFS can be assigned to aerosol parameters and if all other aerosol parameters are known accurately. However, when two DFS are available is not possible to separate SSA from aerosol layer height and particle size. When three or more DFS are available and desert dust aerosol is present, information about the SSA appears to be difficult to separate from information about the particle size, whereas the height information may be separable. These results give an indication for which aerosol parameters to choose when only a subset of aerosol parameters is used as the free fit parameters in the aerosol retrieval and a-priori information is used for the remaining parameters.

The results of the PCA can be used in order to determine the number of DFS for a given reflectance measurement. This quantity can be provided as diagnostic output of the aerosol retrieval using the multi-wavelength algorithm.
Acknowledgements. The authors thank J. F. de Haan (Royal Netherlands Meteorological Institute (KNMI), The Netherlands) and Omar Torres (NASA Goddard Space Flight Center/University of Maryland, USA) for fruitful discussions and valuable comments on an earlier version of the manuscript.

Edited by: W. Conant

\section{References}

Acarreta, J. R. and de Haan, J. F.: Cloud pressure algorithm based on $\mathrm{O}_{2}-\mathrm{O}_{2}$ absorption, OMI Algorithm Theoretical Basis Document: Clouds, Aerosols, and Surface UV Irradiance, Vol. 3, version 2, OMI-ATBD-03, edited by: Stammes, P., http://eospso.gsfc.nasa.gov/eos_homepage/for_ scientists/atbd/docs/OMI/ATBD-OMI-03.pdf, 2002.

Acarreta, J. R., De Haan, J. F., and Stammes, P.: Cloud pressure retrieval using the $\mathrm{O}_{2}-\mathrm{O}_{2}$ absorption band at $477 \mathrm{~nm}$, J. Geophys. Res., 109, D05204, doi:10.1029/2003JD003915, 2004.

Bauman, J.: Stratospheric Aerosol Climatology Derived from Satellite Solar Occultation and Infrared Emission Measurements, Phd Thesis, Institute for Terrestrial and Planetary Atmospheres, State University of New York, Stony Brook, 2000.

Bohren, C. F. and Huffman, D. R.: Absorption and scattering of light by small particles, John Wiley, New York, 1983.

Chandrasekhar, S.: Radiative Transfer, 393 pp., Dover, Mineola, N. Y., 1960.

Chowdhary, J., Cairns, B., Mishchenko, M., and Travis, L.: Retrieval of aerosol properties over the ocean using multispectral and multiangle photopolarimetric measurements from the research scanning polarimeter, Geophys. Res. Lett., 28(2), 243246, 2001.

Deirmendjian, D.: Electromagnetic Scattering on Spherical Polydispersions, American Elsevier Publishing Company, Inc., New York, 1969.

Deuzé, J.-L., Goloub, P., Herman, M., Marchand, A., Perry, G., and Tanré, D.: Estimate of the aerosols properties over the ocean with POLDER, J. Geophys. Res., 105, 15 329-15 346, 2000.

Deuzé, J.-L., Bréon, F.-M., Devaux, C., Goloub, P., Herman, M., Lafrance, B., Maignan, F., Marchand, A., Nadal, F., Perry, G., and Tanré, D.: Remote sensing of aerosols over land surfaces from POLDER-ADEOS 1 Polarized measurements, J. Geophys. Res., 106, 4913-4926, 2001.

Diner, D. J., Abdou, W. A., Ackerman, T. P., Crean, K., Gordon, H. R., Kahn, R. A., Martonchik, J. V., McMuldroch, S., Paradise, S. R., Pinty, B., Verstraete, M. M., Wang, M., and West, R. A.: MISR Level 2 Aerosol Retrieval Algorithm Theoretical Basis http://eospso.gsfc.nasa.gov/eos_homepage/for_scientists/atbd/ docs/MISR/atbd-misr09.pdf, 1999.

Dubovik, O., Holben, B. N., Eck, T. F., Smirnov, A., Kaufman, Y. J., King, M. D., Tanré, D., and Slutsker, I.: Variability of Absorption and Optical Properties of Key Aerosol Types Observed in Worldwide Locations, J. Atmos. Sci., 59, 590-608, 2002.

De Haan, J. F., Bosma, P., and Hovenier, J.: The adding method for multiple scattering computations of polarized light, Astron. Astrophys., 183, 371-393, 1987.

Hansen, J. E. and Travis, L. D.: Light scattering in planetary atmospheres, Space Sci. Rev., 16 527-16 610, 1974. 
Hasekamp, O. P. and Landgraf, J.: Retrieval of aerosol properties over the ocean from multispectral single-viewing-angle measurements of intensity and polarization: Retrieval approach, information content, and sensitivity study, J. Geophys. Res., 101, D20207, doi:10.1029/2005JD006212, 2005.

Herman, J. R. and Celarier, E.: Earth surface reflectivity climatology at 340 and $380 \mathrm{~nm}$ from TOMS data, J. Geophys. Res., 102, 12 059-12 076, 1997.

Hess, M., Koepke, P., and Schult, I.: Optical Properties of Aerosols and Clouds: The Software Package OPAC, Bull. Amer. Meteorol. Soc., 79, 5, 831-844, 1998.

Holben, B., Eck, T. F., Slutsker, I., Tanré, D., Buis, J. P., Setzer, A., Vermote, E., Reagan, J. A., Kaufman, Y., Nakajima, T., Lavenu, F., and Jankowiak, I.: AERONET - A federated instrument network and data archive for aerosol characterization, Rem. Sens. Environ., 66, 1-16, 1998.

Van de Hulst, H. V.: Light scattering by Small Particles, John Wiley, New York, 1957, reprinted by Dover, Mineola, New York, 1981.

Jolliffe, I. T.: Principal Component Analysis, Springer, New York, 1986.

Kerridge, B. J., Siddans, R., Reburn, W. J., Remedios, J. J., Richards, N. A. D., Dudhia, A., et al.: Definition of mission objectives and observational requirements for an Atmospheric Chemistry Explorer mission, Final Report, ESA Contract 13048/98/NL/GD, ESTEC, Noordwijk, The Netherlands, 2001.

Knap, W. H., Labonnote, L. C., Brogniez, G., and Stammes, P.: Modeling total and polarized reflectances of ice clouds: evaluation by means of POLDER and ATSR-2 measurements, Appl. Opt., 44(19), 4060-4073, 2005.

Koelemeijer, R. B. A., de Haan, J. F., and Stammes, P.: A database of spectral surface reflectivity in the range $335-772 \mathrm{~nm}$ derived from 5.5 years of GOME observations, J. Geophys. Res., 108(D2), 4070, doi:10.1029/2002JD002429, 2003.

Levelt, P. F., Hilsenrath, E., Leppelmeier, G. W., van den Oord, G. H. J., Bhartia, P. K., Tamminen, J., de Haan, J. F., and Veefkind, J. P.: Science Objectives of the Ozone Monitoring Instrument, IEEE Trans Geo. Rem. Sens., 44(5), 1199-1208, 2006a.

Levelt, P. F., van den Oord, G. H. J., Dobber, M. R., Mälkki, A., Visser, H., de Vries, J., Stammes, P., Lundell, J. O. V., and Saari, H.: The Ozone Monitoring Instrument, IEEE Trans Geo. Rem. Sens., 44(5), 1093-1101, 2006b.

Masuda, K., Mano, Y., Ishimoto, H., Tokuno, M., Yoshizaki, Y., and Okawara, N.: Assessment of the nonsphericity of mineral dust from geostationary satellite measurements, Rem. Sens. Environ., 82, 238-247, 2002.

Mishchenko, M. I., Geogdzhayev, I. V., Cairns, B., Rossow, W. B., and Lacis, A. A.: Aerosol retrievals over the ocean by use of channels 1 and 2 AVHRR data: sensitivity analysis and preliminary results, Appl. Opt., 38, 7325-7341, 1999.

Mishchenko, M. I., Lacis, A. A., Carlson, B. E., and Travis, L. D.: Nonsphericity of dust-like tropospheric aerosol: implications for aerosol remote sensing and climate modelling, Geophys. Res. Lett., 22, 1077-1080, 1995.
Patterson, E. M., Gillette, D. A., and Stockton, B. H.: Complex index of refraction between 300 and $700 \mathrm{~nm}$ for Saharan aerosol, J. Geophys. Res., 82, 3153-3160, 1977.

Rodgers, C.: Inverse Methods for Atmospheric Sounding: Theory and Practice, World Sci., River Edge, N. J., 2000.

Sinyuk, A., Torres, O., and Dubovik, O.: Combined use of satellite and surface observations to infer the imaginary part of the refractive index of Saharan dust, Geophys. Res. Lett., 30(2), 53-1, 1081, doi:10.1029/2002GL016189, 2003.

Stammes, P., de Haan, J., and Hovenier, J.: The polarized internal radiation field of a planetary atmosphere, Astron. Astrophys., 225, 239-259, 1989.

Stammes, P.: Spectral radiance modelling in the UV-Visible range: IRS 2000: Current problems in Atmospheric Radiation, edited by: Smith, W. L. and Timofeyev, Y. M., A. Deepak Publ., Hampton (VA), 2001.

Tanré, D., Herman, M., and Kaufman, Y. J.: Information on aerosol size distribution contained in solar reflected spectral radiances, J. Geophys. Res., 101(D14), 19043-19060, 1996.

Tanré, D., Kaufman, Y. J., Herman, M., and Matoo, S.: Remote sensing of aerosol properties over oceans using the MODIS/EOS spectral radiances, J. Geophys. Res., 102, $16971-$ 16988, doi:10.1029/96JD03437, 1997.

Torres, O., Bhartia, P. K., Herman, J. R., and Ahmad, Z.: Derivation of aerosol properties from satellite measurements of backscattered ultraviolet radiation. Theoretical Basis, J. Geophys. Res., 103, 17 099-17 110, 1998.

Torres, O., Bhartia, P. K., Herman, J. R., Sinyuk, A., and Holben, B.: A long term record of aerosol optical thickness from TOMS observations and comparison to AERONET measurements, J. Atmos. Sci., 59, 398-413, 2002a.

Torres, O., Decae, R., Veefkind, J. P., and de Leeuw, G.: OMI Aerosol Retrieval Algorithm, OMI Algorithm Theoretical Basis Document: Clouds, Aerosols, and Surface UV Irradiance, Vol. 3, version 2, OMI-ATBD-03, edited by: Stammes, P., http://eospso.gsfc.nasa.gov/eos_homepage/for scientists/atbd/docs/OMI/ATBD-OMI-03.pdf, 2002 b.

Veihelmann, B., Volten, H., and van der Zande, W. J.: Light reflected by an atmosphere containing irregular mineral dust aerosol, Geophys. Res. Lett., 31, L04113, doi:10.1029/2003GL018229, 2004.

Vermote, E. F. and Vermeulen, A.: Atmospheric correction algorithm: Special reflectances (MOD09), ATBD version 4.0, available at: http://modis-land.gsfc.nasa.gov/mod09/, 1999.

Volten, H., Muñoz, O., Rol, E., de Haan, J. F., Vassen, W., Hovenier, J. W., Muinonen, K., and Nousiainen, T.: Scattering matrices of mineral particles at $441.6 \mathrm{~nm}$ and $632.8 \mathrm{~nm}$, J. Geophys. Res., 106(D15), 17 375-17401, 2001. 